\title{
PRUEBAS DE CREATIVIDAD
}

\author{
Máximo LUI LAM CAMPOS \\ Universidad Ricardo Palma \\ maximo.luicam@urp.edu.pe
}

\section{RESUMEN}

La presente investigación es de carácter tecnológico, basados en un modelo integral de la creatividad, se presentan diversas pruebas que se pueden utilizar para evaluarla, como a sus diversas sub-variables, cada prueba seleccionada responde a un marco teórico que más que mostrar su superioridad o cientificidad son complementarios en la investigación y formación del conocimiento científico. Se presenta el test de Pensamiento Creativo de Torrance, la prueba de Evaluación de los indicadores Básicos de Creatividad (EIBC-R), la prueba de Imaginación Creativa - PIC-J, Test de los 8 tipos de la Creatividad y finalmente un test tipo lista de cotejo para conocer si se es más o menos. Estos instrumentos aportarán en la construcción de más instrumentos para investigar el fenómeno de la creatividad.

\section{PALABRAS CLAVE}

Creatividad, proceso creativo, producto creativo y niveles de creatividad.

\section{CREATIVITYTESTS}

\section{ABSTRACT}

The present research is of a technological nature, based on an integral model of creativity, the various tests that can be used to evaluate it are presented, as well as its various sub-variables, each selected test responds to a theoretical framework that more than to show its superiority or scientificity, are complementary in the investigation of scientific knowlegde. The Torrance Creative Thinking test is presented, the Basic Indicators of Creativity Assessment test (EIBC-R), the Creative Imagination test - PIC-J, the Test of the 8 types of Creativity and finally a list-type test, check to know if you are more or less creative. These instruments will contribute to the construction of more instruments to investigate the phenomenon of creativity.

\section{KEYWORDS}

Creativity, creative process, creative product and levels of creativity. 


\section{Introducción}

Dentro del mundo de la creatividad -ya sea en ámbitos artísticos, en el campo de la ciencia o en el sector de la tecnología- existen múltiples perfiles creativos definidos por el carácter del individuo, su formación y su sistema de trabajo, esto lleva a contar con diversos instrumentos que nos den una visión más amplia de lo evaluamos y así promover mejor el desarrollo creativo evitando generalizaciones falaces sobre quien es o no creativo.

Estos instrumentos presentados, como todo en las ciencias fácticas son mejorables y perfectibles, ya no se tiene que empezar desde cero como en el siglo pasado, se pueden utilizar como antecedentes que aportaron y aportaran para la construcción de más instrumentos que permitan investigar en diversos niveles el fenómeno de la creatividad que ha sido revalorada este siglo.

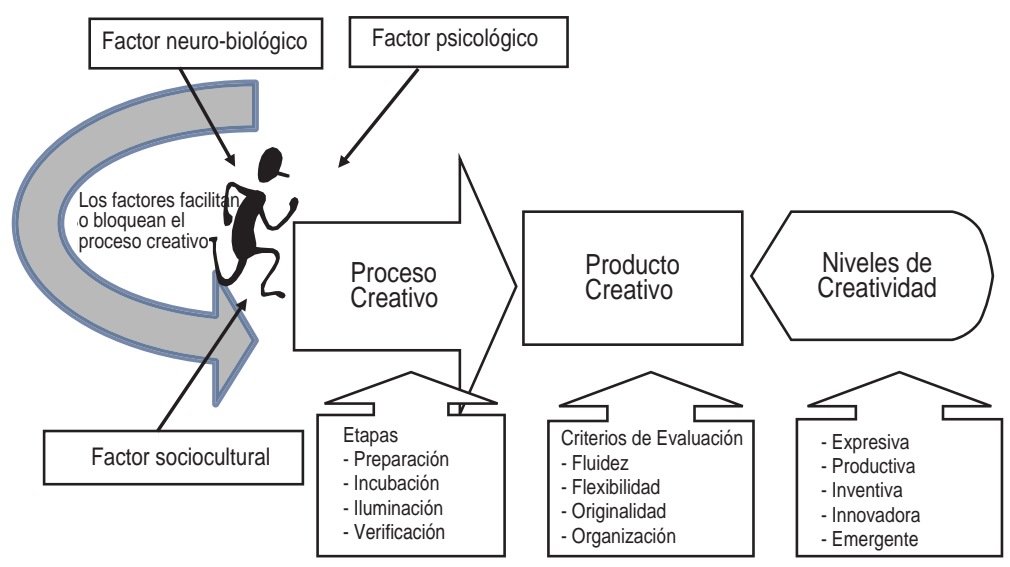

Figura 01. Modelo Integral de la Creatividad de Lui Lam

Test de Pensamiento Creativo'Torrance' (TTCT)

Apellidos y Nombres: Edad: Sexo:

\section{Instrucciones}

\section{Acabamos un dibujo}

"Sobre esta página y la siguiente encontrarás dibujos incompletos, añadiendo elementos; puedes representar cosas interesantes: objetos, imágenes, lo que tú quieras. Desarrolla tu primera idea con el fin de ilustrar una historia lo más completa e interesante posible. Intenta encontrar ideas en las que nadie haya pensado antes. Recuerda escribir, debajo de cada dibujo, el título que le hayas dado". 


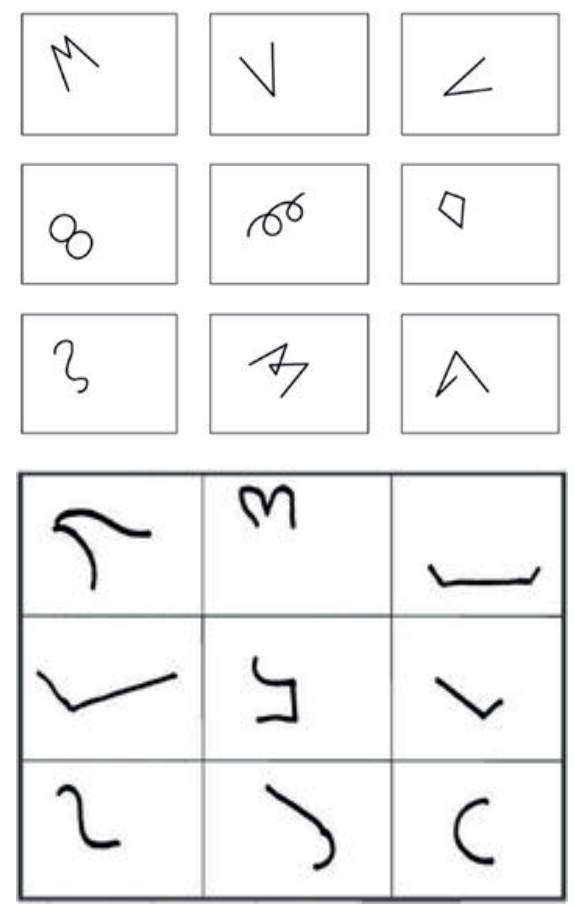

Otra prueba elaborada por Sánchez Carlessi desde 1988 hasta la fecha en sus versiones para niños y jóvenes, trata de evaluar los factores o sub-variables como: fluidez (cuántas opciones puede llegar usted a conseguir), originalidad (usos menos frecuentes), flexibilidad (en cuántas áreas se mueve, por ejemplo, pendientes y gemelos estarían dentro de una misma área porque son objetos similares) y elaboración (detalle en las respuestas). Los modelos de los ítems son los siguientes:

\section{Prueba para evaluar indicadores básico de creatividad EIBC-R}

Apellidos y Nombres:

Edad: Sexo:

Lugar de residencia: Distrito:

Grado de estudio: Primaria: Secundaria: Superior:

\section{Instrucciones}

A continuación, te vamos a presentar una serie de indicaciones ante las cuales deberás poner en juego toda tu imaginación posible.

Escribe sobre los espacios señalados. Se te dará el tiempo suficiente para que des tus respuestas, pero no te demores demasiado.

Piensa bien en tus respuestas tratando de imaginarte aquello que para ti puede resultar lo más original y novedoso. 


\section{Sub Test I}

1. Pon a prueba tu imaginación y escribe en los espacios en blanco la mayor cantidad de objetos que puedan servir como herramientas. $\left(2^{\prime \prime}\right)$

2. Pon en juego tu imaginación y escribe todo lo que puedas hacer con un zapato. (2")

\section{Sub Test II}

3. Escribe sobre la línea punteada todo lo que hace que un ratón y un gato se parezcan. ( $\left(2^{\prime \prime}\right)$

4. Escribe todo lo que hace que un reloj y una máquina de escribir se parezcan. (2")

Sub Test III

5. Imagínate y escribe en los espacios en blanco todas las formas en que puedes mejorar un perrito de trapo. $\left(2^{\prime \prime}\right)$

6. Imagínate y escribe en los espacios en blanco todos los usos posibles que puede dársele a los autos viejos inservibles. (2")

\section{Sub Test IV}

7. Imagínate y escribe en los espacios en blanco todo lo que pasaría si el sol desapareciera. ( $\left.3^{\prime \prime}\right)$

8. Imagínate y escribe en los espacios en blanco todo lo que pasaría si el hombre pudiera volar. $\left(3^{\prime \prime}\right)$

\section{Sub Test $V$}

9. Pon en juego tu imaginación y escribe un cuento breve a partir de las siguientes palabras: (3") Mercado ---- Dinero ---- Mamá

10. Pon en juego tu imaginación y escribe un cuento a partir de las siguientes palabras: (3") Trabajo ---- Escuela ---- Profesión

Sub Test VI

11. Mira bien el dibujo y escribe en los espacios en blanco todo lo que el dibujo te hace imaginar. (3")

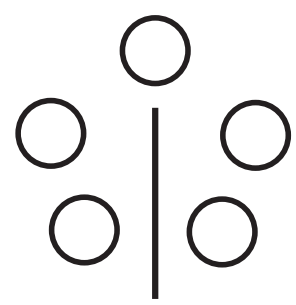

12. Mira bien el dibujo y escribe en los espacios en blanco todo lo que el dibujo te hace imaginar. (3")

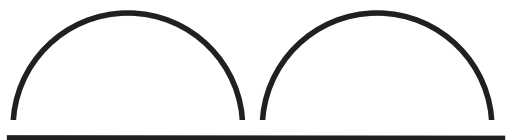




\section{Sub Test VII}

13. Pon en juego tu imaginación y has un dibujo interesante a partir de esta figura. Cuando termines ponle nombre a tu dibujo. (3")

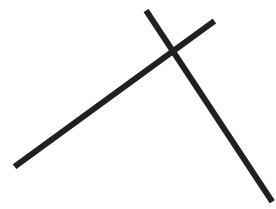

14. Pon en juego tu imaginación y has un dibujo interesante a partir de esta figura. Cuando termines ponle nombre a tu dibujo. $\left(3^{\prime \prime}\right)$

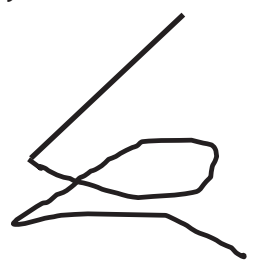

Surgen otros enfoques de creatividad que desde la psicología cognitiva la llaman Inteligencia Creativa, entre ellos tenemos a Corbalán, Martínez y Donolo (2015) con su test CREA que busca una medida cognitiva de la creatividad, la que se presenta a continuación.

\section{Crea}

Apellidos y Nombres:

Edad: Sexo: Fecha:

Centro de estudio: Grupo:

\section{Instrucciones}

No abra este ejemplar hasta que se lo indique

Se les va a presentar una ilustración. Su tarea consiste en escribir brevemente cuantas preguntas le sea posible hacer sobre lo que representa. Trate de hace el mayor número posible.

Se trata de elaborar preguntas, cuantas más mejor.

Trate de ajustarse a los espacios para responder pero si por las características de su escritura no le resulta cómodo, no se preocupe, no es lo importante.

A continuación se presentan algunos modelos de las imágenes que se utilizan en las pruebas según niveles de los evaluados:
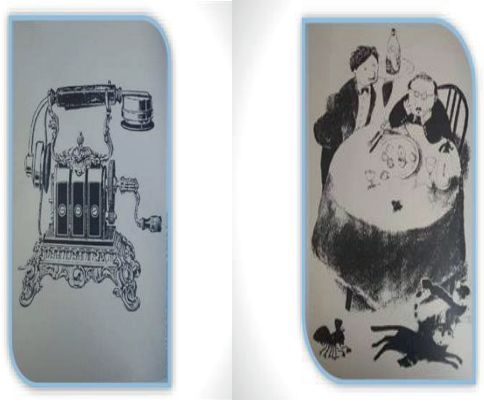
Otra prueba publicada en TEA Ediciones por Artola, Ancillo, Mosterio y Barraca (2004), se titula Prueba de Imaginación Creativa - PIC, en sus versiones para niños, jóvenes y adultos. Los ítems se presentan a continuación:

\section{Prueba de Imaginación Creativa - PIC - J}

Apellidos y Nombres: Edad: Sexo: Fecha:

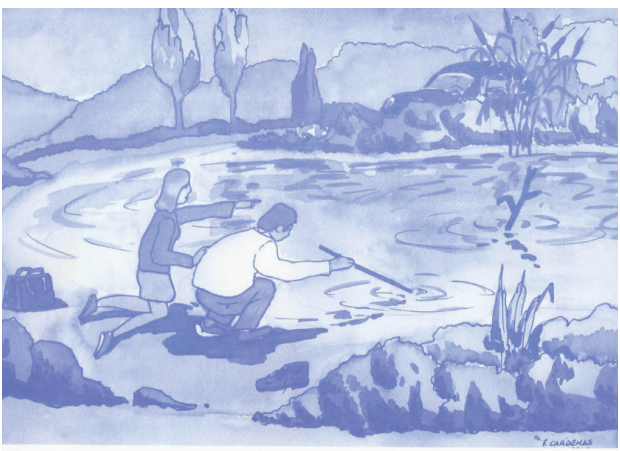

\section{Juego $\mathbf{N}^{\circ} 1$}

Fíjate en la lámina que aparece en la página anterior. Tu tarea consiste en imaginar todo aquello que podría estar ocurriendo en esa escena, Escribe todo lo que se te ocurra. Ten en cuenta que en este juego no existen respuestas correctas o incorrectas, así que pon en marcha tu imaginación y fantasía y procura poner muchas ideas.

\section{Ejemplo: "Es una aventura en un lago".}

\section{Juego $\mathrm{N}^{\circ} 2$}

Haz una lista de todas las cosas para las que podría servir un tubo de goma. Piensa en cosas interesantes y originales. Apunta todos los usos que tú le darías aunque sean imaginados. Puedes utilizar el número y tamaño que tú quieras.

\section{Ejemplo: "Como tubería para el agua".}

\section{Juego $N^{\circ} 3$}

Imagínate y contesta lo que tú crees que pasaría si ocurriese lo que dice esta frase: ¿Qué ocurriría si de repente, el suelo se volviera elástico?

Ejemplo: "Que estaríamos todo el día botando". 


\section{Juego $\mathrm{N}^{\circ} 4$}

En esta página puedes ver unos dibujos incompletos. Intenta completarlos haciendo con ellos un dibujo tan original que a nadie más se le hubiera ocurrido. Después pon un título interesante a cada uno de los dibujos.
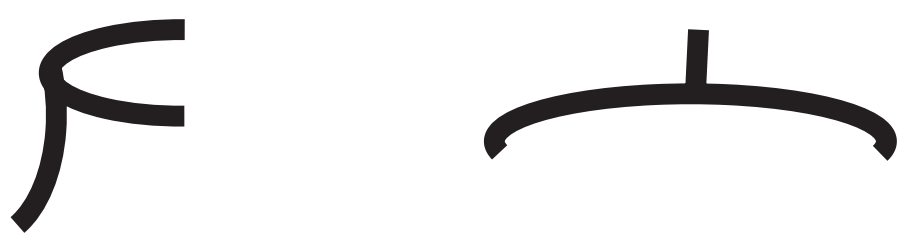

1.

2.
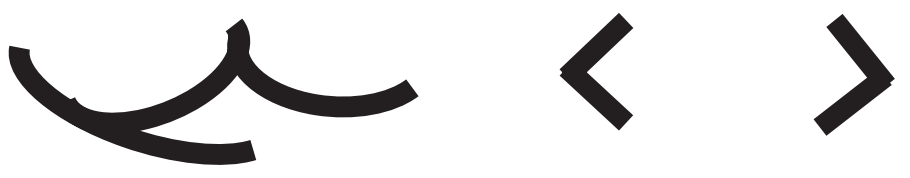

3.

4.

Cuando se empieza a hablar de tipos de creatividad, tenemos un primer intento de Taylor (Citado por Sánchez, 2003) de identificar cinco niveles de creatividad las que nombra de la siguiente manera:

a) Creatividad expresiva, que corresponde al primer nivel, siendo la forma más elemental, se da de manera espontánea, afectiva, natural y con amplia libertad. En este nivel prima la expresión libre, presentando algunos vestigios de originalidad.

b) Creatividad productiva, que corresponde al segundo nivel. Aquí se encuentran definidos los rasgos de originalidad, sin que difieran de modo notorio de otras personas. Implica la presencia de habilidades y destrezas que llevan a la construcción técnica. Se manifiesta de manera práctica, cuando el individuo se enfrenta a su realidad, resolviendo problemas prácticos, haciendo uso de recursos técnicos o de tecnología intermedia que conoce y domina.

c) Creatividad inventiva, se ubica en el tercer nivel. Se da cuando se presentan componentes propios u originales de manera definida y el individuo se relaciona de modo nuevo con su realidad, llegando a inventos prácticos tomando como base los aportes de la ciencia y la tecnología.

d) Creatividad innovadora, se ubica en el cuarto nivel. Incluye una profunda comprensión científica de los principios fundamentales de un campo problemático, no se mide en el mundo de las experiencias concretas del individuo que crea, sino, en ámbitos culturales o científicos más amplios. Supone una capacidad inventiva que contribuye o aporta significativamente a la humanidad.

e) Creatividad emergente, es el quinto y más elevado nivel del producto creativo, y comprende la formación de nuevas escuelas teórico-científicas, la total reestructuración de 
otras experiencias, implica la capacidad de recibir nuevas exposiciones y reorganizarlas, de abstraerlas y sintetizarlas. El producto creativo lo ubicamos en el caso de las revoluciones científicas y tecnológicas, las mismas que se han ido presentando a través de las historias y continúan hasta el presente.

Otra prueba que intenta describir los tipos creativos es la Jason Theodor (2012), quien afirma que todos las personas son creativas, pero lo son de distinta manera e intensidad, para ello elabora una prueba para describirlas, considerando tres elementos que pueden variar en dimensión y combinación, generando estos 8 tipos creativos.

Theodor (2012) considera que la creatividad está compuesta por tres elementos que determinan en su conjunto la fuerza de la creatividad: Acción (hace referencia al hacer, el romper las barreras de las cantidades), conexión (es pegar, conectar o enlazar) y desviación (referida al sesgar, distorsionar o irse por los lados no comunes). El plantea la idea de que no se trata de hacerse más creativos, se trata de ser más creativos. A continuación se grafica su modelo de la siguiente manera: (Ver figura 02 y 03)

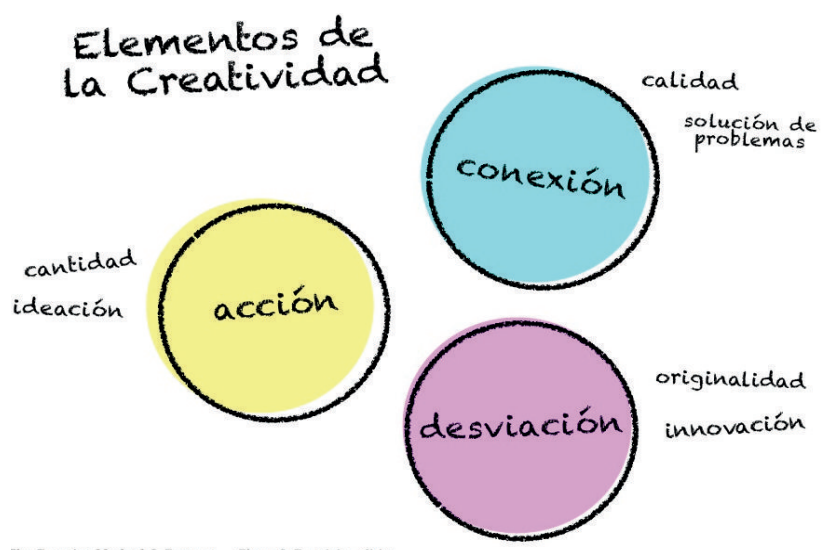

Figura 02. Elementos de la Creatividad

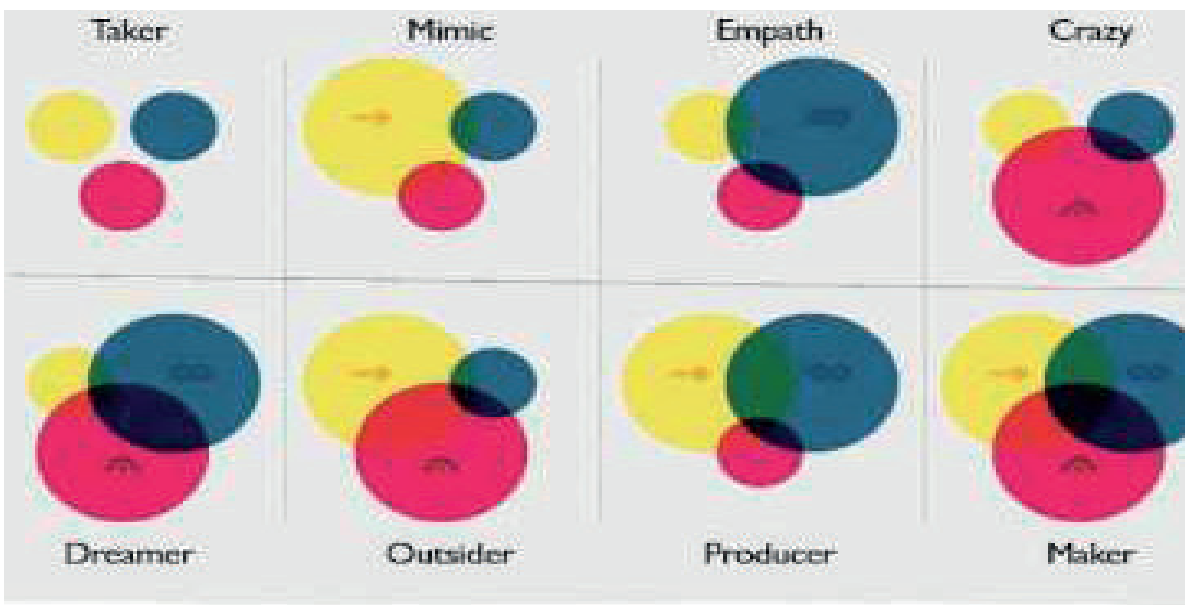

Figura 03. Tipos de creatividad 


\section{Test de los 8 tipos de creatividad de Jason theodor}

Apellidos y Nombres:

Edad:

Fecha:

Distrito de residencia: Facultad / Carrera:

\section{Instrucciones}

Solo recuerda, esto no es una prueba de personalidad o de trabajo, se trata de su enfoque, su estilo, su estado predeterminado, trate de responder lo más rápido y sincero/a posible.

\begin{tabular}{|c|c|c|}
\hline Preguntas de acción & CIERTO & FALSO \\
\hline 1. "Hacer o no hacer. Aquí no hay intentos." & & \\
\hline $\begin{array}{l}\text { 2. Siento temor cuando miro a un papel en blanco / hoja de } \\
\text { cálculo / pantalla / lienzo porque no estoy seguro de cómo } \\
\text { empezar o de dónde van a venir las ideas. }\end{array}$ & & \\
\hline $\begin{array}{l}\text { 3. Rara vez siento el impulso creativo de hacer algo. Me gustaría } \\
\text { estar más contento viendo la televisión o jugando videojuegos. }\end{array}$ & & \\
\hline 4. Casi siempre tengo algunos proyectos en movimiento. & & \\
\hline $\begin{array}{l}\text { 5. No tengo una rutina consistente para hacer las cosas. En su } \\
\text { lugar, sólo ala y espero lo mejor. }\end{array}$ & & \\
\hline $\begin{array}{l}\text { 6. Tengo una tendencia a postergar. A veces incluso aplazar mis } \\
\text { procrastinaciones. Esto hace que sea muy difícil terminar un } \\
\text { proyecto. }\end{array}$ & & \\
\hline $\begin{array}{l}\text { 7. Trabajo muy duro en mi arte. Puse en el tiempo, incluso cuando } \\
\text { no me siento inspirado. }\end{array}$ & & \\
\hline $\begin{array}{l}\text { 8. Hacer algo lo suficientemente bueno y terminarlo es aún } \\
\text { mejor que hacer algo grande pero nunca completarlo. }\end{array}$ & & \\
\hline $\begin{array}{l}\text { 9. No tengo miedo de fallar. El fracaso es sólo otra palabra para } \\
\text { el aprendizaje. }\end{array}$ & & \\
\hline $\begin{array}{l}\text { 10. Mi método preferido de aprendizaje es hacerlo yo mismo en } \\
\text { lugar de mirar a los demás o leer sobre ello en un libro. }\end{array}$ & & \\
\hline Preguntas de conexión & & \\
\hline $\begin{array}{l}\text { 11. Paso mucho tiempo pensando en lo que voy a hacer, en lugar } \\
\text { de hacerlo. }\end{array}$ & & \\
\hline $\begin{array}{l}\text { 12. Traiga cualquier palabra o tema al azar, y todavía tendré algo } \\
\text { que decir al respecto. }\end{array}$ & & \\
\hline $\begin{array}{l}\text { 13. Es importante obtener los detalles correctos. El menor matiz } \\
\text { puede causar el mayor impacto. }\end{array}$ & & \\
\hline
\end{tabular}




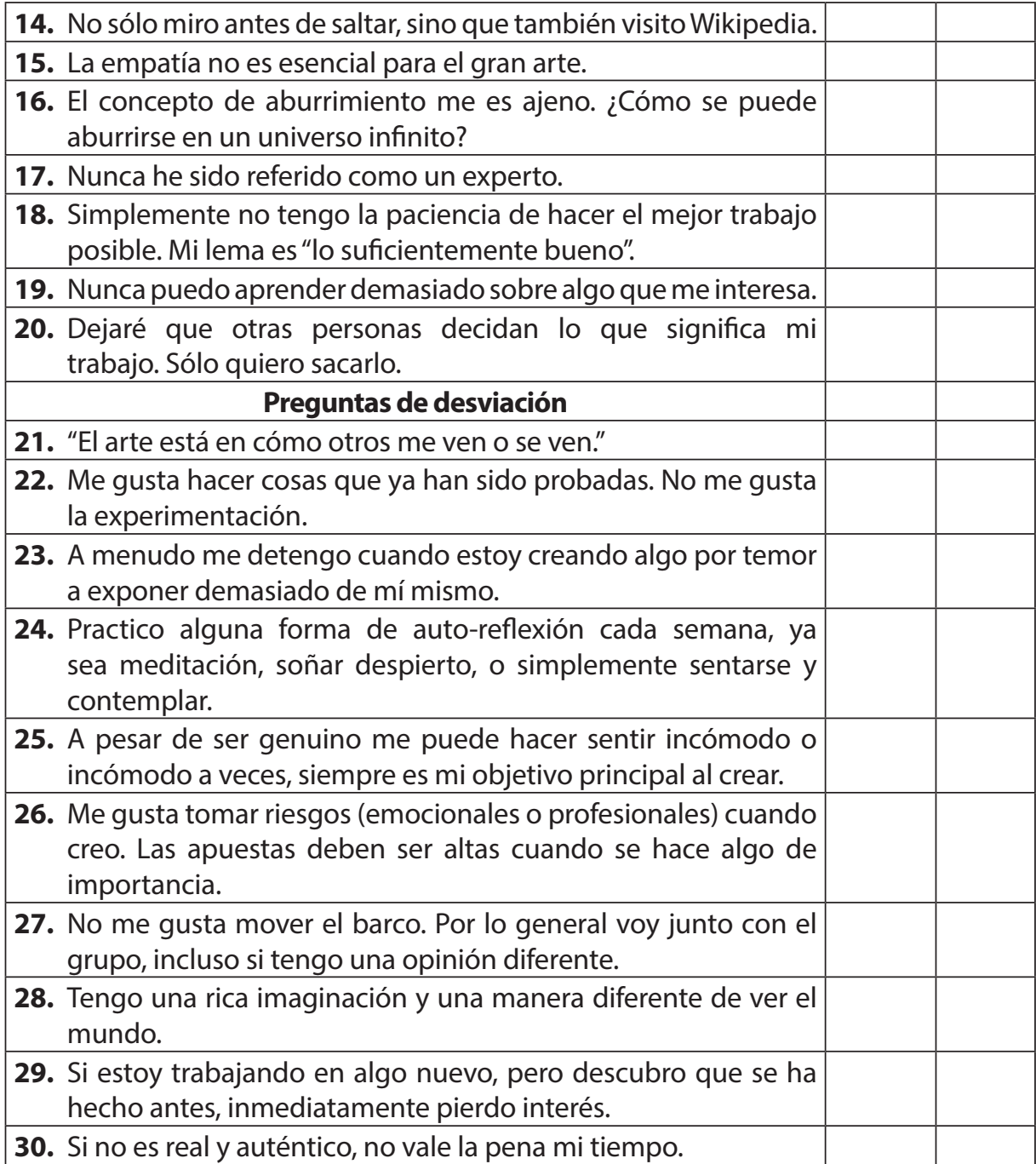

\section{Resumen de interpretación}

Según el puntaje obtenido por componentes se pueden obtener ocho combinaciones posibles que se describen brevemente a continuación: 


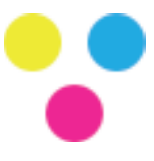

\section{El Aprendiz Creativo (acd)}

- Siente un impulso para ser creativo, pero aún no ha adquirido la gama completa de habilidades, conocimientos o confianza para obtener consistentemente los resultados deseados.

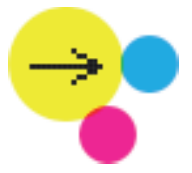

\section{El Profesional (Acd)}

- Sabe cómo empezar y cómo terminar.

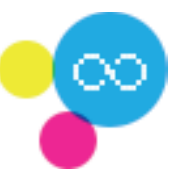

\section{El Filósofo $(\mathrm{aCd})$}

- Puede ver y comprender el panorama general.

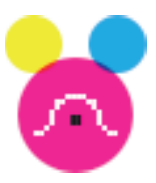

\section{El temerario (acD)}

- Presenta originalidad a través de la auto-expresión sin miedo.

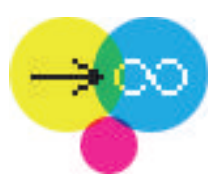

\section{El Productor (ACd)}

- Sabe exactamente cómo hacer que todo funcione.

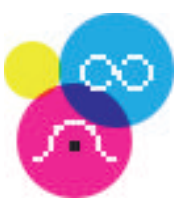

\section{El Soñador (aCD)}

- Un gran pensador con ideas sorprendentes.

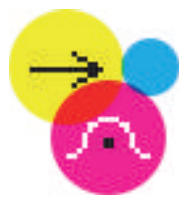

\section{El Rebelde (AcD)}

- Actúa rápidamente sobre la intuición y no se preocupa por los detractores.

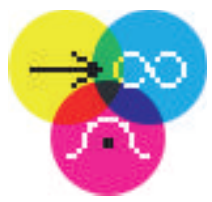

\section{El Maestro (ACD)}

- Una rutina creativa establecida, una comprensión aguda de su arte, y una profunda confianza en su expresión. Otros instrumentos tipo cuestionario intentan dar un alcance de los niveles creativos por una autoevaluación, a continuación se presentan algunos modelos: 


\section{TEST PARA CONOCER SI SE ES MÁS O MENOS CREATIVO}

Apellidos y Nombres:

Edad:

Fecha:

Distrito de residencia:

Facultad/Carrera:

Para conocer tu nivel de creatividad deberás marcar en la tabla con una x la respuesta correcta. Una vez hayas contestado todas las preguntas, deberás sumar los puntos de las respuestas y con el total podrás ver si eres más o menos creativo.

La última vez que recuerdo....

\begin{tabular}{|l|l|l|}
\hline \multicolumn{1}{|c|}{ Pregunta } & \multicolumn{1}{|c|}{ PTOS } & MARCA \\
\hline 1. A alguien diciéndome: “Tu nunca habías pensado o hecho eso antes" \\
\hline a) No me acuerdo & 1 & \\
\hline b) Hace más de un año & 2 & \\
\hline c) En algún momento del último año & 3 & \\
\hline d) El mes pasado & 4 & \\
\hline e) Me ocurre con frecuencia & 5 & \\
\hline
\end{tabular}

2. Que cambié mi rutina sin una razón particular más que el haber querido hacer otras cosas

\begin{tabular}{|l|l|l|}
\hline a) No me acuerdo & 1 & \\
\hline b) Hace más de un año & 2 & \\
\hline c) En algún momento del último año & 3 & \\
\hline d) El mes pasado & 4 & \\
\hline e) Me ocurre con frecuencia & 5 & \\
\hline
\end{tabular}

3. Que reacomodé las cosas de mi cuarto, de mi oficina, de mi casillero o de mi mesa de noche, solo por diversión

\begin{tabular}{|l|l|l|}
\hline a) No me acuerdo & 1 & \\
\hline b) Hace más de un año & 2 & \\
\hline c) En algún momento del último año & 3 & \\
\hline d) El mes pasado & 4 & \\
\hline e) Me ocurre con frecuencia & 5 & \\
\hline
\end{tabular}

4. A alguien que me estaba diciendo: "eso no se puede hacer" o"eso no tiene arreglo" o "no vale la pena, déjalo así" pero yo no le hice caso y seguí intentándolo

\begin{tabular}{|l|l|l|}
\hline a) No me acuerdo & 1 & \\
\hline b) Hace más de un año & 2 & \\
\hline c) En algún momento del último año & 3 & \\
\hline d) El mes pasado & 4 & \\
\hline e) Me ocurre con frecuencia & 5 & \\
\hline
\end{tabular}




\begin{tabular}{|c|c|c|}
\hline \multicolumn{3}{|l|}{ 5. Que luché por una causa, una idea, un ideal } \\
\hline a) No me acuerdo & 1 & \\
\hline b) Hace más de un año & 2 & \\
\hline c) En algún momento del último año & 3 & \\
\hline d) El mes pasado & 4 & \\
\hline e) Me ocurre con frecuencia & 5 & \\
\hline \multicolumn{3}{|l|}{ 6. Que estuve equivocado } \\
\hline a) No me acuerdo & 1 & \\
\hline b) Hace más de un año & 2 & \\
\hline c) En algún momento del último año & 3 & \\
\hline d) El mes pasado & 4 & \\
\hline e) Me ocurre con frecuencia & 5 & \\
\hline \multicolumn{3}{|c|}{ 7. Que me decían "estás equivocado" porque intenté algo nuevo } \\
\hline a) No me acuerdo & 1 & \\
\hline b) Hace más de un año & 2 & \\
\hline c) En algún momento del último año & 3 & \\
\hline d) El mes pasado & 4 & \\
\hline e) Me ocurre con frecuencia & 5 & \\
\hline \multicolumn{3}{|l|}{ 8.Que hice algo que me puso muy nervioso } \\
\hline a) No me acuerdo & 1 & \\
\hline b) Hace más de un año & 2 & \\
\hline c) En algún momento del último año & 3 & \\
\hline d) El mes pasado & 4 & \\
\hline e) Me ocurre con frecuencia & 5 & \\
\hline \multicolumn{3}{|c|}{ 9. Que hice algo que me causó temor y al mismo tiempo emoción y alegría } \\
\hline a) No me acuerdo & 1 & \\
\hline b) Hace más de un año & 2 & \\
\hline c) En algún momento del último año & 3 & \\
\hline d) El mes pasado & 4 & \\
\hline e) Me ocurre con frecuencia & 5 & \\
\hline \multicolumn{3}{|c|}{ 10. Que salí de un aprieto que me tenía en el limbo } \\
\hline a) No me acuerdo & 1 & \\
\hline b) Hace más de un año & 2 & \\
\hline c) En algún momento del último año & 3 & \\
\hline d) El mes pasado & 4 & \\
\hline e) Me ocurre con frecuencia & 5 & \\
\hline
\end{tabular}




\section{REFERENCIAS BIBLIOGRÁFICAS}

Artola y otros (2004). Prueba de Imaginación Creativa Manual. Madrid: TEA Ediciones.

Corbalan, Martínez y Donolo (2015) Crea. Inteligencia Creativa. Una medida cognitiva de la creatividad. Manual. Madrid: TEA. Ediciones.

De La Torre, S., y Violant, V. (coord. y dir.) (2006). Comprender y evaluar la creatividad, vol. 1. Málaga, España: Ediciones Aljibe.

Lui Lam C., M. (1995). "Inteligencia, Creatividad y Ajuste Psicosocial en Niños Superdotados y Talentosos. Tesis para optar la Licenciatura de Psicología. Universidad Ricardo Palma. Lima, Perú.

Sánchez C., H. (2003). Psicología de la Creatividad. Lima: Editorial Visión Universitaria.

Theodor, J. (2012). The 8 creative types presentation. Extraído el 28/06/17 de http:// jasontheodor.com/2012/04/30/the-8-creative-types-presentation/

UPC (2017) Creatividad Empresarial. http://creatividadempresarial.upc.edu.pe/

PQS Portal Fundación Romero (2017) UPC presenta el Premio Creatividad Empresarial 2017.

http://www.pqs.pe/emprendimiento/upc-presenta-premio-creatividad-empresarial-2017. 